\title{
Serum Galectin-3 Levels in Children with Attention-Deficit/Hyperactivity Disorder
}

\author{
Ümit Işık ${ }^{1 \otimes}$, Faruk Kılıç ${ }^{2}$, Arif Demirdaş², Evrim Aktepe', and Pınar Aydoğan Avşar ${ }^{1}$ \\ ${ }^{1}$ Department of Child and Adolescent Psychiatry, Suleyman Demirel University Faculty of Medicine, Isparta, Turkey \\ ${ }^{2}$ Department of Psychiatry, Suleyman Demirel University Faculty of Medicine, Isparta, Turkey
}

\begin{abstract}
Objective Attention-deficit/hyperactivity disorder (ADHD) is a neurodevelopmental disorder with underlying pathogenesis and etiological factors not fully understood. We assumed that galectin-3, which is also linked with inflammatory responses, may play an important role in the ethiopathogenesis of ADHD. In this study, we aimed to investigate whether serum galectin-3 levels are related to ADHD in childhood.

Methods The current study consisted of 35 treatment-naive children with ADHD and 35 control subjects. The severities of ADHD and conduct disorder symptoms were assessed via parent- and teacher-rated questionnaires. The severity of anxiety and depression symptoms of the children were determined by the self-report scale. Venous blood samples were collected and serum galectin-3 levels were measured.

Results The ADHD group had significantly higher serum Galectin-3 levels than the control group. To control confounding factors, including age, sex, and BMI percentile, one-way analysis of covariance (ANCOVA) test was also performed. Analyses revealed a significantly higher serum log- Galectin-3 levels in children with ADHD compared to controls. No association was found between the mean serum galectin-3 levels and sociodemographic characteristics and clinical test scores, except the oppositional defiant behavior scores.
\end{abstract}

Conclusion Our research supports the hypothesis that serum levels of galectin-3 might be related to ADHD.

Psychiatry Investig 2020;17(3):256-261

Key Words Attention-deficit/hyperactivity disorder, Galectin-3, Inflammatory mediators.

\section{INTRODUCTION}

Attention-deficit/hyperactivity disorder (ADHD) is a neurodevelopmental disorder characterized by persistent and maladaptive symptoms of hyperactivity/impulsivity and inattention. ${ }^{1}$ The most prevalent neurodevelopmental disorder in childhood, ADHD, affects approximately $6-8 \%$ of children., ${ }^{2,3}$ In a multicenter study conducted in Turkey, ADHD prevalence in elementary school student has been identified as $12.4 \%$. The underlying pathogenesis and etiological factors of ADHD remains unclear, but are probably multifactorial, including genetic causes, functional and structural brain circuitry differences, and environmental and psychosocial variables. ${ }^{5-8}$ One of the

\footnotetext{
Received: September 20, 2019 Revised: November 13, 2019

Accepted: December 24, 2019

$\triangle$ Correspondence: Ümit Işık, MD

Department of Child and Adolescent Psychiatry, Suleyman Demirel University Faculty of Medicine, Isparta 32260, Turkey

Tel: +9024621193 46, E-mail: crsumt@gmail.com

(a) This is an Open Access article distributed under the terms of the Creative Commons Attribution Non-Commercial License (https://creativecommons.org/licenses/bync/4.0) which permits unrestricted non-commercial use, distribution, and reproduction in any medium, provided the original work is properly cited.
}

interesting study subjects in this context is the inflammatory system. ${ }^{8,9}$ Due to positive results concerning inflammation-related parameters, several researchers have suggested a connection between $\mathrm{ADHD}$ and inflammatory mechanisms. ${ }^{8-11}$

Galectins represent a family of proteins with 15 or more members that have substantial sequence similarity in their carbohydrate recognition domain and are bound with b-galactosides with different affinities and specificities. ${ }^{12,13}$ Among the known galectin proteins, galectin-3, the most explored and unique family member, is found in various types of cells and tissues and its different functions have been described, such as promoting cell migration, stimulating role in proliferation, differentiation, survival, adhesion, apoptosis, and immune responses. ${ }^{14,15}$ It is also involved in inflammation as a proinflammatory mediator and has been extensively researched in various inflammatory conditions. ${ }^{15,16}$ There is now an ongoing effort to investigate the significance of galectin-3 in relation to nervous system diseases. Much attention has been focused on neurological and cerebrovascular disease. ${ }^{17-19}$ Interest has increased over the past few years in the relationship between galectin-3 and psychiatric disorders. To our knowledge, in patients with schizophrenia, 
two studies examined serum galectin- 3 concentrations. ${ }^{20,21}$ In one of these studies, Kajitani et al., ${ }^{20}$ detected increased serum galectin- 3 concentration in patients with schizophrenia. In another study, Borovcanin et al., ${ }^{21}$ reported that the concentrations of galectin-3 were elevated in remission and lower in exacerbation of schizophrenia compared to controls. To the best of our knowledge, there are only two studies in ADHD that examine galectin-3 concentrations. ${ }^{22,23}$ Wu et al., ${ }^{22}$ demonstrated lower galectin-3 levels in spontaneously hypertensive rats brain prefrontal cortex compared to Wistar-Kyoto rats. In another study performed by the same group, they detected low galectin-3 levels in ADHD cases. ${ }^{23}$ In these studies, the authors proposed that detection of galectin-3 might be useful in the clinical assessment of ADHD. ${ }^{22,23}$

Several studies have shown that inflammatory agents are enhanced in patients with ADHD, indicating the connection between inflammation and ADHD. ${ }^{8-10}$ However, to our knowledge, only a few studies have examined the connection between ADHD and galectin-3. Having regard to these results, we assumed that galectin-3, which is also linked with inflammatory responses, may play an important role in the ethiopathogenesis of ADHD. We measured galectin-3 concentrations in children with $\mathrm{ADHD}$ to examine this assumption.

\section{METHODS}

\section{Subjects}

This research was carried out in child and adolescent psychiatry outpatient clinic at the Suleyman Demirel University Medicine Faculty. The research population consisted of 35 children aged between 8 and 12 and diagnosed with ADHD prior to treatment. The criteria for exclusion regarded any major psychiatric comorbidity including autism spectrum disorder, mental retardation, bipolar disorder, and schizophrenia; serious somatic comorbidity, particularly current infections, metabolic disorders, autoimmune disorders, and neurological disorders. Participants who had taken psychiatric medication in the last year were also excluded. The comparison group was consisted of healthy volunteers. In healthy children, the same diagnostic criteria, process and exclusion criteria as ADHD were used to exclude ADHD and major psychiatric disorders. Thirty-five $\mathrm{ADHD}$ patients and 35 healthy volunteers were matched in age (8-12 years) and sex. All participants and their families were volunteers, and the procedures were in line with local ethics committee requirements and endorsed by Suleyman Demirel University Medicine Faculty (2019/352). Once information about the research was provided, informed written consent was acquired from parents of children.

\section{Diagnostic and symptom assessment}

Participants were given a survey form prepared by the researchers, consisting of questions on sociodemographic and clinical data. The Schedule for Affective Disorders and Schizophrenia for School-Aged Children, Present and Lifetime Version (K-SADS-PL) was administered both the target child and a parent. ${ }^{24,25}$ The diagnosis of ADHD were made according to the DSM- 5 criteria by child and adolescent psychiatrists during clinical interviews. ${ }^{1}$ The parents and teachers of the participants completed the Turgay DSM-IV-Based Child and Adolescent Behavioral Disorders Screening and Rating Scale (TDSM-IV-S) for the assessment of ADHD and levels of disruptive behavior symptoms of the children. ${ }^{26,27}$ Participants completed the Turkish version of the Revised Child Anxiety and Depression Scale-Child Version (RCADS-CV) to determine the level of anxiety and depression of children. ${ }^{28}$ The height and weight of children were registered for each participant.

\section{Collection of blood samples}

Participants were invited to give blood samples between 8.00-10.00 hours after fasting at night. After fasting for at least 8 hours without caloric consumption, blood specimens were taken into serum separator tubes by venipuncture from each participant. After completion of clotting, blood samples were centrifuged at 4,000 rpm for $5 \mathrm{~min}$. The serum samples were carefully separated after centrifugation and reserved at $-80^{\circ} \mathrm{C}$ to study serum galectin-3 concentrations until the study day. The Eppendorf tubes were carried to room temperature on the day of biochemical analysis and allowed the frozen serum to settle. Serum galectin-3 concentrations were measured with a commercially available enzyme-linked immunosorbent assay (ELISA) kit according to the manufacturer's protocol (Elabscience Instant ELISA kit ref: E-EL-H1470; lot: SW84C6YPRA). This ELISA kit uses the Sandwich-ELISA principle. Galectin-3 concentrations in the samples were calculated in $\mathrm{ng} / \mathrm{mL}$.

\section{Statistical analysis}

The chi-square test was used to analyse differences between groups in sex. Variables are shown either as a number (n) or as a mean \pm standard deviation (SD). Kolmogorov-Smirnov test was carried out to investigate data distribution and further statistical analysis was carried out using parametric and nonparametric tests. The patients' and controls' ages and BMI percentiles were compared with the independent samples t-test. Because of abnormal distributions of psychometric test scores and serum galectin-3 levels, the Mann-Whitney U test was used. The natural logarithm transformation was used for serum galectin-3 concentrations with skewed distribution before the one-way analysis of covariance (ANCOVA). The normal distribution of log-galectin-3 was confirmed by the Kolmogorov- 
Smirnov test. ANCOVA was conducted for possible confounding variables. The ANCOVA analyses was carried out with adjustments for age, sex, and the body mass index (BMI) percentile. The correlation between serum concentrations of galectin-3 and sociodemographic and clinical variables was assessed by the Spearman rank correlation coefficient. Differences with p-value less than 0.05 (two-tailed) were considered as statistical significance. The statistical analyses was carried out using the software SPSS 20 (IBM Corp., Armonk, NY, USA).

Table 1. Demographic and clinical characteristics of children with $\mathrm{ADHD}$ and healthy controls

\begin{tabular}{lccll}
\hline & $\begin{array}{c}\text { Children with } \\
\text { ADHD (N=35) }\end{array}$ & $\begin{array}{c}\text { Controls } \\
(\mathrm{N}=35)\end{array}$ & $\mathrm{t} / \mathrm{z} / \chi^{2}$ & $\mathrm{p}$ \\
\hline Age, years & $9.5 \pm 1.3$ & $9.8 \pm 1.5$ & $-0.784^{*}$ & 0.436 \\
Sex, male/female & $24 / 11$ & $24 / 11$ & $0.0^{\ddagger}$ & 1 \\
BMI percentile & $62.8 \pm 30$ & $63.5 \pm 29.8$ & $-0.108^{*}$ & 0.914 \\
T-DSM-IV-S: parent & & & & \\
AD & $19.1 \pm 4.7$ & $4.7 \pm 3.1$ & $-7.089^{\dagger}$ & $<0.001$ \\
HA/I & $16.9 \pm 6.2$ & $4.3 \pm 3.5$ & $-6.566^{\dagger}$ & $<0.001$ \\
OD & $13 \pm 6.2$ & $4.8 \pm 3.8$ & $-5.391^{\dagger}$ & $<0.001$ \\
CD & $2.8 \pm 2.7$ & $0.4 \pm 1$ & $-4.706^{\dagger}$ & $<0.001$
\end{tabular}

T-DSM-IV-S: teacher

$\begin{array}{lrrrr}\mathrm{AD} & 17.3 \pm 5.4 & 4.5 \pm 3.3 & -6.861^{\dagger} & <0.001 \\ \mathrm{HA} / \mathrm{I} & 14.2 \pm 8.5 & 2.4 \pm 1.7 & -5.821^{\dagger} & <0.001 \\ \mathrm{OD} & 9.3 \pm 6.6 & 2.5 \pm 2.3 & -4.967^{\dagger} & <0.001 \\ \mathrm{CD} & 3 \pm 4.3 & 0.2 \pm 0.6 & -4.153^{\dagger} & <0.001\end{array}$

RCADS-CV

\begin{tabular}{lrrrr} 
GAD & $6.9 \pm 4.1$ & $2.7 \pm 3.1$ & $-4.700^{\dagger}$ & $<0.001$ \\
SP & $10 \pm 7.2$ & $5.5 \pm 5.7$ & $-2.626^{\dagger}$ & 0.009 \\
SAD & $6.8 \pm 5.1$ & $3.2 \pm 2.7$ & $-2.981^{\dagger}$ & 0.003 \\
PD & $7.2 \pm 7.3$ & $2.6 \pm 4.3$ & $-3.785^{\dagger}$ & $<0.001$ \\
OCD & $6.1 \pm 4.6$ & $3.6 \pm 2.6$ & $-2.212^{\dagger}$ & 0.027 \\
MDD & $8.8 \pm 6.1$ & $3 \pm 3.1$ & $-4.670^{\dagger}$ & $<0.001$ \\
\hline
\end{tabular}

${ }^{*}$ student $\mathrm{t}$ test, ${ }^{\dagger}$ Mann-Whitney $\mathrm{U}$ test, ${ }^{\ddagger}$ chi-square test. ADHD: attention-deficit/hyperactivity disorder, T-DSM-IV-S: Turgay DSM IV-Based Child and Adolescent Behavioral Disorders Screening and Rating Scale, AD: attention-deficit, HA/I: Hyperactivity-Impulsivity, OD: Oppositional Defiant Behavior, CD: Conduct Disorder, RCADS-CV: Revised Child Anxiety and Depression Scale-Child Version (Turkish), SAD: separation anxiety disorder, GAD: generalized anxiety disorder, PD: panic disorder, SP: social phobia, OCD: obsessive-compulsive disorder, MDD: major depressive disorder

\section{RESULTS}

The current study consisted of 35 children ( 24 boys/ 11 girls) with $\mathrm{ADHD}$ and 35 control subjects ( 24 boys/11 girls) $\left(\chi^{2}=\right.$ $0.000 ; \mathrm{p}=1.000)$. The mean age of ADHD (9.5 \pm 1.3 years $)$ and control (9.8 \pm 1.5 years) groups did not differ significantly (range: $8-12$ years; $\mathrm{t}=-0.784 ; \mathrm{p}=0.436)$. In addition, the mean BMI percentile did not differ between the groups $(t=-0.108 ; \mathrm{p}=0.914)$. Participants in the ADHD group had significantly higher scores on all subscales of RCADS-CV and parents and teacher rated T-DSM-IV-S than the comparison group. The demographic characteristics and clinical data of the participants are presented in Table 1.

The ADHD group had significantly higher serum Galectin-3 concentrations than the control group $(1.20 \pm 0.78$ vs. $0.78 \pm$ $0.37 \mathrm{ng} / \mathrm{mL} ; \mathrm{z}=-2.303, \mathrm{p}=0.021$ ) (Figure 1, Table 2). To control confounding factors, including age, sex, and BMI percentile, an ANCOVA test was also performed. Analyses revealed significantly higher serum log- Galectin-3 concentrations [F (1, $\left.65)=8.731, \mathrm{p}=0.004, \eta_{\mathrm{p}}{ }^{2}=0.118\right]$ in children with ADHD compared to controls.

Furthermore, the correlation between the mean galectin-3 serum concentrations and, the age, sex, and BMI percentile and the mean of the RCADS-CV and teacher and parent rated T-DSM-IV-S subscales, and the total scores were investigated in the ADHD group. No association was found between the mean serum galectin-3 concentrations and sociodemo-

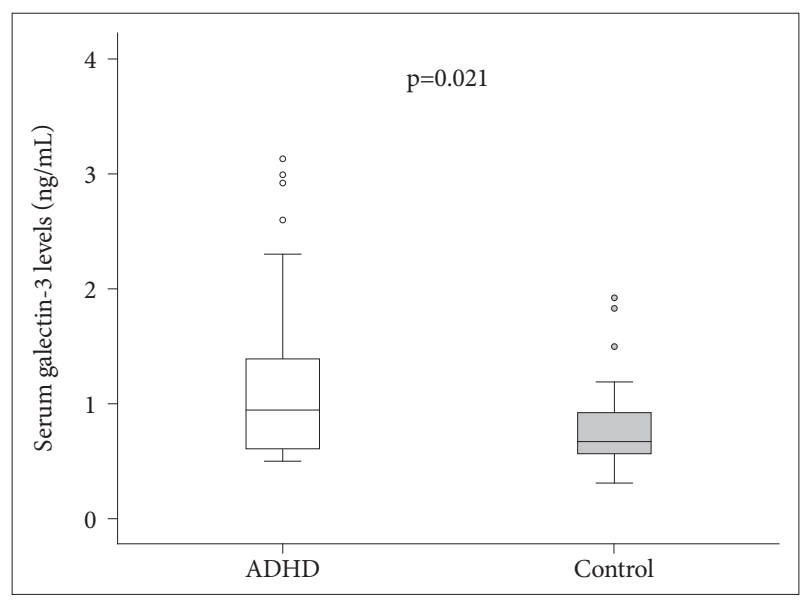

Figure 1. Box plots representing the distribution of serum Galectin-3 levels in ADHD and controls. ADHD: attention-deficit/hyperactivity disorder.

Table 2. Serum Galectin-3 levels of children with ADHD and healthy controls

\begin{tabular}{|c|c|c|c|c|c|c|c|}
\hline & \multirow{2}{*}{ Children with ADHD $(\mathrm{N}=35)$} & \multirow{2}{*}{ Controls $(\mathrm{N}=35)$} & \multicolumn{2}{|c|}{ Mann-Whitney U } & \multicolumn{3}{|c|}{ ANCOVA* } \\
\hline & & & $\mathrm{z}$ & $\mathrm{p}$ & $\mathrm{F}$ & $\mathrm{p}$ & $\eta_{\mathrm{p}}{ }^{2}$ \\
\hline Galectin-3 (ng/mL) & $1.20 \pm 0.78$ & $0.78 \pm 0.37$ & -2.303 & 0.021 & 8.731 & 0.004 & 0.118 \\
\hline
\end{tabular}


graphic characteristics and clinical test scores, except the parent-rated T-DSM-IV-S oppositional defiant behavior scores $(\mathrm{r}=-0.357, \mathrm{p}=0.035)$.

\section{DISCUSSION}

The current research evaluated whether serum galectin-3 concentrations are related to ADHD in childhood. The findings suggested that children with ADHD had higher galectin-3 serum concentrations than controls, apart from potential confounders including sex, age, and BMI percentile. These findings indicate that serum galectin- 3 concentrations may be associated with the ethiopathogenesis of ADHD.

To date, galectin-3 has been examined as a marker for only a few psychiatric disorders including schizophrenia and $\mathrm{ADHD}^{20-23}$ Schizophrenia and galectin-3 levels has been recently investigated. Kajitani et al. ${ }^{20}$ noted that the galectin-3 serum levels were increased in chronic schizophrenia and were positively correlated with both the brief psychiatry rating scale (BPRS) positive symptom score and activation score and negatively correlated with the BPRS negative symptom score. Borovcanin et al., ${ }^{21}$ recently showed that levels of galectin-3 were lower in firstepisode psychosis and schizophrenia in relapse and higher in schizophrenia in remission than those measured in healthy controls. These authors indicated that galectin-3 levels may play an important role in schizophrenia development and should be examined in other psychiatric disorders. ${ }^{20,21}$ In this context, only two previous studies examined the galectin- 3 levels in the ADHD sample. ${ }^{22,23}$ Wu et al., ${ }^{22}$ demonstrated lower galectin-3 levels in spontaneously hypertensive rats brain prefrontal cortex as compared with Wistar-Kyoto rats. In another study performed by the same group, they detected low galectin-3 levels in ADHD cases. ${ }^{23}$ In this study, the authors detected high expression of galectin-3 in only eight patients and showed low expression of galectin- 3 in 23 out of 35 ADHD subjects. ${ }^{23}$ In contrast to ADHD studies, in our research, similar to schizophrenia studies, serum galectin-3 concentrations were considerably higher in the ADHD group than in the control group. Furthermore, in our research, serum galectin- 3 concentrations were found to be negatively correlated with the oppositional defiant behavior scores in the ADHD group. When the above studies were examined, brain prefrontal cortex of spontaneously hypertensive rats was examined in one of the studies ${ }^{22}$ and serum galectin- 3 levels in Western Blot method were examined in the other study. ${ }^{23}$ The difference between our study and the results of these studies may be due to these methodological differences.

Increased galectin- 3 concentrations in the ADHD group indicate that galectin-3 may play a part in the etiopathogenesis of ADHD. However, it is currently unknown why in this re- search, serum galectin-3 concentrations were elevated in children with ADHD and were associated with the oppositional defiant behavior scores. The effect of the amount of physical activity on circulating galectin-3 may be one possible mechanism that may underlie the association between the increased galectin-3 concentrations and ADHD. In a study comparing rheumatoid arthritis patients and controls, the authors found that physical exercise induces galectin-3 release and suggested that cartilage oligomeric matrix protein could lead to an increase in galectin-3 levels after physical exercise. ${ }^{29}$ As it is known, hyperactivity is one of the most important symptom cluster in $\mathrm{ADHD} .{ }^{1}$ Considering that physical exercise induces galectin-3 increases, increased galectin-3 levels in ADHD group may be associated with increased hyperactivity in $\mathrm{ADHD}$ group. However, our study has not identified any correlation between the hyperactivity scale scores and galectin-3 levels in both the ADHD group and the whole sample. Therefore, future studies may be able to shed some light on the link between galectin-3 concentrations and hyperactivity.

Another possible mechanism underlying the association between serum galectin- 3 concentrations and $\mathrm{ADHD}$ is changes in inflammatory parameters in ADHD. Galectin-3 is clearly important in nervous system development and neuroinflammation. ${ }^{8-10}$ Galectin-3 has been reported to play a crucial role with both pro and anti-inflammatory actions in inflammatory pathways. ${ }^{30,31}$ The data are consistent with a connection between the peripheral inflammatory parameters and ADHD. Recent evidence suggests that patients with ADHD have higher serum cytokine levels than controls. ${ }^{9,11,32,33}$ Galectin-3 was suggested to lead to increased inflammatory response by suppressing the anti-inflammatory cytokine interleukin-10 (IL-10) production. ${ }^{34} \mathrm{An}$ in vitro survey also documented that galectin-3 induces IL-6 expression, while galectin-3 inhibition decreases IL- $1 \beta$ expression, implying that galectin- 3 regulates the expression concentrations of cytokines associated with ADHD. ${ }^{35,36}$ Because these cytokines are involved in promoting inflammation in the central nervous system, ${ }^{8-10}$ increased galectin-3 may indicate worsening of neuroinflammation in ADHD.

The inclusion of newly diagnosed treatment naïve ADHD patients and controlling age, gender and BMI percentile variables in the analysis are strengths of the current study. However, the findings found in the current study should be evaluated with some limitations. First, since this was a cross-sectional study, we were unable to determine causality or temporal relationships between galectin-3 and ADHD. Further prospective studies are necessary to determine whether this relation is reflective of a causal relationship. Second, the sample size was relatively small and to confirm our results, further research with larger sample sizes are required. Third, we can not expand our 
findings to all ADHD patients because of a restricted age range and a small number of girls. Fourth, we did not follow a change of galectin-3 concentrations over time and measured just a single inflammatory marker; it may be more suitable for measuring the inflammation by serial measurements and using multiple markers. Finally, the cases included in the study were not pure $\mathrm{ADHD}$ cases and comorbid psychiatric disorders were not excluded. Therefore, it is not clear whether increased galectin-3 levels are due to ADHD or psychiatric disorders associated with ADHD. To explain this relationship, studies involving only pure ADHD cases are needed.

Increased serum galectin-3 concentrations might indicate potential inflammation in ADHD patients. These results show that galectin-3 may play an important role in the etiopathogenesis of ADHD. Additional studies involving a larger population and addressing our study limitations are required, and further research is needed into the causal relationship between galectin-3 levels and ADHD.

\section{Acknowledgments}

None.

\section{Conflicts of Interest}

The authors have no potential conflicts of interest to disclose.

\section{Author Contributions}

Conceptualization: Ümit Işık, Faruk Kılıç. Data curation: Ümit Işsk, Faruk Kılıı̧, Pınar Aydoğan Avşar. Formal analysis: Ümit Işık, Faruk Kılıç. Funding acquisition: Ümit Işıı, Faruk Kılıç, Arif Demirdaş, Pınar Aydoğan Avşar. Investigation: Ümit Işık, Faruk Kulıç, Arif Demirdaş, Evrim Aktepe, Pınar Aydoğan Avşar. Methodology: Ümit Işık, Faruk Kılıç, Arif Demirdaş, Evrim Aktepe, Pınar Aydoğan Avşar. Project administration: Ümit Işık. Resources: Ümit Işık, Faruk Kılıç, Arif Demirdaş, Evrim Aktepe, Pınar Aydoğan Avşar. Software: Ümit Ișık, Faruk Kılıç, Arif Demirdaş, Evrim Aktepe, Pınar Aydoğan Avşar. Supervision: Ümit Işık. Validation: Ümit Işık, Faruk Kılıç, Arif Demirdaş, Evrim Aktepe, Pınar Aydoğan Avşar. Visualization: Ümit Işık, Faruk Kılıç, Arif Demirdaş, Evrim Aktepe, Pınar Aydoğan Avşar. Writing_original draft: Ümit Işık. Writing_review \& editing: Ümit Işık, Faruk Kılıç, Arif Demirdaş, Evrim Aktepe, Pınar Aydoğan Avşar.

\section{ORCID iDs}

$\begin{array}{ll}\text { Ümit Işılk } & \text { https://orcid.org/0000-0001-6006-3247 } \\ \text { Faruk Kılıç } & \text { https://orcid.org/0000-0002-2259-4028 } \\ \text { Arif Demirdaş } & \text { https://orcid.org/0000-0002-2548-2224 } \\ \text { Evrim Aktepe } & \text { https://orcid.org/0000-0002-3082-4428 } \\ \text { Pınar Aydoğan Avşar } & \text { https://orcid.org/0000-0001-5938-3243 }\end{array}$

\section{REFERENCES}

1. American Psychiatric Association: Diagnostic and Statistical Manual of Mental Disorders: Diagnostic and Statistical Manual of Mental Disorders, Fifth Edition. Arlington, VA: American Psychiatric Association, 2013

2. Willcutt EG. The prevalence of DSM-IV attention-deficit/hyperactivity disorder: a meta-analytic review. Neurotherapeutics 2012;9:490-499.

3. Thomas R, Sanders S, Doust J, Beller E, Glasziou P. Prevalence of attention-deficit/hyperactivity disorder: a systematic review and metaanalysis. Pediatrics 2015;135:e994-e1001.
4. Ercan ES, Polanczyk G, Akyol Ardıc U, Yuce D, Karacetın G, Tufan AE, et al. The prevalence of childhood psychopathology in Turkey: a cross-sectional multicenter nationwide study (EPICPAT-T). Nord J Psychiatry 2019;73:132-140.

5. Thapar A, Cooper M, Eyre O, Langley K. Practitioner review: What have we learnt about the causes of ADHD? J Child Psychol Psychiatry 2013;54:3-16.

6. Thapar A, Cooper M. Attention deficit hyperactivity disorder. Lancet 2015;6736:1-11.

7. Faraone SV, Bonvicini C, Scassellati C. Biomarkers in the diagnosis of ADHD - promising directions. Curr Psychiatry Rep 2014;16:497.

8. Dunn GA, Nigg JT, Sullivan EL. Neuroinflammation as a risk factor for attention deficit hyperactivity disorder. Pharmacol Biochem Behav 2019;182:22-34.

9. Anand D, Colpo GD, Zeni G, Zeni CP, Teixeira AL. Attention-deficit/ hyperactivity disorder and inflammation: what does current knowledge tell us? A systematic review. Front Psychiatry 2017;8:1-7.

10. Leffa DT, Torres ILS, Rohde LA. A review on the role of nflammation in attention-deficit/hyperactivity disorder. Neuroimmunomodulation 2018;25:328-333.

11. Donfrancesco R, Nativio P, Di Benedetto A, Villa MP, Andriola E, Melegari MG, et al. Anti-yo antibodies in children with ADHD. J Atten Disord pii: 1087054716643387. [Epub ahead of print]

12. Barondes SH, Cooper DN, Gitt MA, Leffler H. Galectins. Structure and function of a large family of animal lectins. J Biol Chem 1994;269: 20807-20810.

13. Yang RY, Rabinovich GA, Liu FT. Galectins: structure, function and therapeutic potential. Expert Rev Mol Med 2008;10:e17.

14. Dumic J, Dabelic S, Flögel M. Galectin-3: an open-ended story. Biochim Biophys Acta 2006;1760:616-635.

15. Almkvist J, Karlsson A. Galectins as inflammatory mediators. Glycoconj J 2002;19:575-581.

16. Hsu DK, Yang RY, Pan Z, Yu L, Salomon DR, Fung-Leung WP, et al. Targeted disruption of the Galectin-3 gene results in attenuated peritoneal inflammatory responses. Am J Pathol 2000;156:1073-1083.

17. Venkatraman A, Callas P, McClure LA, Unverzagt F, Arora G, Howard $\mathrm{V}$, et al. Galectin-3 and incident cognitive impairment in REGARDS, a cohort of blacks and whites. Alzheimer's Dement Transl Res Clin Interv 2018;4:165-172.

18. Doverhag C, Hedtjärn M, Poirier F, Mallard C, Hagberg H, Karlsson A, et al. Galectin-3 contributes to neonatal hypoxic-ischemic brain injury. Neurobiol Dis 2010;38:36-46.

19. Rahimian R, Béland LC, Kriz J. Galectin-3: mediator of microglia responses in injured brain. Drug Discov Today 2018;23:375-381.

20. Kajitani K, Yanagimoto K, Nakabeppu Y. Serum galectin-3, but not galectin-1, levels are elevated in schizophrenia: implications for the role of inflammation. Psychopharmacology (Berl) 2017;234:2919-2927.

21. Borovcanin MM, Janicijevic SM, Jovanovic IP, Gajovic N, Arsenijevic NN, Lukic ML. IL-33/ST2 pathway and galectin-3 as a new analytes in pathogenesis and cardiometabolic risk evaluation in psychosis. Front Psychiatry 2018;9:271.

22. Wu L, Zhao Q, Zhu X, Peng M, Jia C, Wu W, et al. A novel function of MicroRNA Let-7d in regulation of galectin-3 expression in attention deficit hyperactivity disorder rat brain. Brain Pathol 2010;20:10421054.

23. Wu LH, Peng M, Yu M, Zhao QL, Li C, Jin YT, et al. Circulating MicroRNA Let-7d in attention-deficit/hyperactivity disorder. Neuromolecular Med 2015;17:137-146.

24. Gökler B, Ünal F, Pehlivantürk B, Cengel Kultur E, Devrim Akdemir D, Taner Y. Reliability and validity of schedule for affective disorders and schizophrenia for school age children-present and lifetime version-Turkish version (K-SADS-PL-T). Turkish J Child Adolesc Ment Heal 2004;11:109-116.

25. Kaufman J, Birmaher B, Brent D, Rao U, Flynn C, Moreci P, et al. Schedule for affective disorders and schizophrenia for school-age chil- 
dren-present and lifetime version (K-SADS-PL): Initial reliability and validity data. J Am Acad Child Adolesc Psychiatry 1997;36:980-988.

26. Ercan ES, Amado S, Somer O, Çıkoğlu S. Development of a test battery for the assessment of attention deficit hyperactivity disorder [in Turkish]. J Child Adolesc Ment Health 2001;8:132-144.

27. Turgay A. Disruptive Behavior Disorders Child and Adolescent Screening and Rating Scales for Children, Adolescents, Parents and Teachers. West Bloomfield, MI: Michigan Integrative Therapy Institute Publication; 1994.

28. Gormez V, Kılınçaslan A, Cahid Orengul A, Ebesutani C, Kaya I, Ceri $\mathrm{V}$, et al. Psychometric properties of the Turkish version of the Revised Child Anxiety and Depression Scale-Child Version in a clinical sample. Psychiatry Clin Psychopharmacol 2017;27:84-92.

29. Filer A, Bik M, Parsonage GN, Fitton J, Trebilcock E, Howlett K, et al. Galectin 3 induces a distinctive pattern of cytokine and chemokine production in rheumatoid synovial fibroblasts via selective signaling pathways. Arthritis Rheum 2009;60:1604-1614.

30. Boscher C, Dennis JW, Nabi IR. Glycosylation, galectins and cellular signaling. Curr Opin Cell Biol 2011;23:383-392.

31. Yu F, Finley RL, Raz A, Kim HRC. Galectin-3 translocates to the perinuclear membranes and inhibits cytochrome $\mathrm{c}$ release from the mito- chondria. A role for synexin in galectin-3 translocation. J Biol Chem 2002;277:15819-15827.

32. Darwish AH, Elgohary TM, Nosair NA. Serum interleukin-6 level in children with attention-deficit hyperactivity disorder (ADHD). J Child Neurol 2019;34:61-67.

33. O'Shea TM, Joseph RM, Kuban KCK, Allred EN, Ware J, Coster T, et al. Elevated blood levels of inflammation-related proteins are associated with an attention problem at age 24 mo in extremely preterm infants. Pediatr Res 2014;75:781-787.

34. Jiang HR, Al Rasebi Z, Mensah-Brown E, Shahin A, Xu D, Goodyear CS, et al. Galectin-3 deficiency reduces the severity of experimental autoimmune encephalomyelitis. J Immunol 2009;182:1167-1173.

35. Chen C, Duckworth CA, Zhao Q, Pritchard DM, Rhodes JM, Yu LG. Increased circulation of galectin-3 in cancer induces secretion of metastasis-promoting cytokines from blood vascular endothelium. Clin Cancer Res 2013;19:1693-1704.

36. Chen SS, Sun LW, Brickner H, Sun PQ. Downregulating galectin-3 inhibits proinflammatory cytokine production by human monocyte-derived dendritic cells via RNA interference. Cell Immunol 2015;294:4453. 